\title{
Radio-ulnar synostosis-amegakaryocytic thrombocytopenia syndrome
}

INSERM

\section{Source}

INSERM. (1999). Orphanet: an online rare disease and orphan drug data base. Radio-ulnar synostosis-amegakaryocytic thrombocytopenia syndrome. ORPHA:71289

Radio-ulnar synostosis-amegakaryocytic thrombocytopenia syndrome is characterised by the association of proximal fusion of the radius and ulna with congenital amegakaryocytic thrombocytopaenia. Less than 10 cases have been reported in the literature so far. The syndrome is transmitted as an autosomal dominant trait and is caused by mutations in the HOXA11 gene (7p15). 